\title{
Genetic Diversity Analysis of Five Egyptian Buffalo Populations Using Microsatellite Markers
}

\author{
S. M. Merdan ${ }^{1}$, M. F. El-Zarei ${ }^{1,2}$, A. A. Ghazy ${ }^{1}$, M. A. Ayoub ${ }^{1}$, Z. M. Al-Shawa ${ }^{1} \&$ S. A. Mokhtar ${ }^{1}$ \\ ${ }^{1}$ Department of Animal Production, Faculty of Agriculture, Suez Canal University, Ismailia, Egypt \\ ${ }^{2}$ Department of Animal Production and Breeding, College of Agriculture and Veterinary Medicine, Qassim \\ University, Buraydah, Saudi Arabia \\ Correspondence: M. F. El-Zarei, Department of Animal Production and Breeding, College of Agriculture and \\ Veterinary Medicine, Qassim University, Buraydah 51452, Saudi Arabia. Tel: 966-6380-0050 Ext. 2287. E-mail: \\ zray@qu.edu.sa
}

Received: January 28,2020

Accepted: February 28, $2020 \quad$ Online Published: March 15, 2020

doi:10.5539/jas.v12n4p271

URL: https://doi.org/10.5539/jas.v12n4p271

\begin{abstract}
For assessing the genetic diversity and genetic characterization of five Egyptian buffalo populations a total of 12 microsatellite markers were used. The total number of buffaloes sampled was 80 , collected at random from five farms in five different governorates; Cairo, Kafr El-Sheikh, Shebeen El-Kom, Menoufia, and Beni Suef. The genetic parameters (allelic diversity, allelic frequencies, observed heterozygosity, unbiased expected heterozygosity, and polymorphic information content) were calculated using three different programs. All used microsatellites were polymorphic and ranged from four alleles (Loci; CSSM029, CSSM036, CSSM038, CSSM043, CSSM046, and ILSTS005) to nine alleles (Loci; BM1818 and CSSM047) with a total of 64 alleles in the whole population. Allelic richness for the whole population ranged between 3.297 (in locus CSSM029) and 6.806 (in locus CSSM047) with overall mean 4.574. Within populations, Kafr El-Sheikh population had the highest average of allelic richness (4.384). This indicates the potential of this population to adapt with environmental changes in future compared with other populations. BMC1013, BM1818, CSSM019, and CSSM047 showed the highest allelic richness. PIC estimates were high and ranged between 0.65 (in locus CSSM029) and 0.92 (in locus CSSM022) with an average of 0.82. Values of $H_{o}$ were lower than values of $H_{\mathrm{Nb}}$ for all populations, which denoting depression of heterozygotes in these populations and may be attributable to existence of null alleles and inbreeding. This study as well proves the usefulness of heterologous bovine microsatellite markers in evaluation of the genetic variability in Egyptian buffalo populations due to high polymorphism, informativeness of these markers which can be used to develop future breeding strategies and conservation decisions on our indigenous breed.
\end{abstract}

Keywords: observed heterozygosity, polymorphic information content, unbiased expected heterozygosity

\section{Introduction}

Egyptian buffalo possess a great importance to Egypt due to its great ability of adaptation to various environments such as the tropical climate, excellent nutritional benefits, and resistance to the diseases (Abu ElMagd et al., 2015). In addition, Egyptian buffalo consider as the primary dairy animal in Egypt, and being an important source of red meat (Abou-Bakr et al., 2012; Attia et al., 2014a; Abu El-Magd et al., 2015). Buffalos' production represents $44.26 \%$ and $36 \%$ of the whole production for milk and meat in Egypt, respectively (FAO, 2019). Buffalos' milk is preferred by the Egyptian consumer due to its white color, and high fat percentage (68\%) (Ibrahim, 2012; Al-Hosary et al., 2015; Abu El-Magd et al., 2015).

Developments in DNA technologies have made it possible to uncover a large number of genetic polymorphisms at the DNA sequence level, and to use them as markers for the evaluation of the genetic basis for the observed phenotypic variability (Jakhesara et al., 2010; Othman et al., 2012). As well, genetic markers provide information about allelic variation at a given locus. The increasing of molecular markers availability in farm animals allows the detailed analyses and evaluation of genetic diversity and furthermore the detection of genes influencing economically important traits. The majority of molecular markers used nowadays with high-throughput systems are microsatellite markers (Erhardt \& Weimann, 2007). The use of microsatellites has become a standard method to estimate genetic diversity in livestock, because of their unique genetic properties 
(Erhardt \& Weimann, 2007; Athe et al., 2018). There are a considerable number of genetic diversity studies for many livestock species were carried out by several investigators from all over the world. However, only a few of these studies (El-Kholy et al., 2007; Abou-Bakr et al., 2012) investigate the genetic diversity using microsatellites analysis in Egyptian buffalo. Genetic characterization of this breed is still incomplete which is very important for conservation decisions and designing future breeding policies.

Therefore, genetic improvement of Egyptian buffalo which of economic importance, especially in milk production could be achieved through the use of molecular genetic information in selection programs which have the potential to increase productivity, enhance environmental adaptation, maintain genetic diversity, and allow early selection to reduce generation intervals (Naqvi, 2007; Sikka \& Sethi, 2008).

The present study was designed to assessing the genetic diversity and genetic characterization of five Egyptian buffalo populations using 12 microsatellite markers.

\section{Materials and Methods}

\subsection{Location}

This study was carried out at Biotechnology Laboratory of Animal Production and Fisheries Department, Faculty of Agriculture, Suez Canal University; Ismailia, Egypt.

\subsection{Selection of Animals and Blood Samples Collection}

Data were collected in agreements with ethical standards, and safety guide procedures. Samples were collected from 80 unrelated lactating buffalo females belonging to five farms in five different governorates over the period from November 2016 through April 2017. These farms were, Agriculture Faculty farm at Cairo University (20 sample), Agricultural Research Station located in Kafr El-Sheikh governorate (29 sample), Shebeen El-Kom Agriculture Faculty farm located in Menoufia governorate (10 samples), Agricultural Research Station located in Ismailia governorate (11 sample), and Sids Research Station located in Beni Suef governorate (10 samples). The blood samples were collected form each animal with a volume of $5 \mathrm{ml}$ in $\mathrm{K}_{3}$ EDTA (as anticoagulant) Vacutainer tubes, placed promptly on a cooling gel in ice box until reaching the Lab, and stored at $-20^{\circ} \mathrm{C}$ until DNA extraction later.

\subsection{DNA Extraction}

DNA was extracted from the whole blood using Quick-gDNATM MiniPrep (50 Preps.) kit, Catalog No. D3024 (Sigma Co.), according to the method described by manufacture.

The quality of DNA yield was evaluated by running in $1 \%$ agarose gel through horizontal gel electrophoreses system. The concentration and purity of DNA for all the samples were quantified using Nano Drop1000 spectrophotometer. Concentration of DNA ranged between 20 and $30 \mathrm{ng} / \mu \mathrm{l}$ and purity of DNA ranged from 1.7 to 1.9 , indicating high quality DNA.

\subsection{Selection of Microsatellites Markers and PCR Amplification}

A total of 15 microsatellite markers were chosen for this study from the cattle genome based on their high polymorphism, polymorphic information content (PIC) with good heterozygosity and information available from previous studies in buffalo (Moore et al., 1995; Barker et al., 1997; Moioli et al., 2001; Tantia et al., 2006; Elbeltagy et al., 2008; Zhang et al., 2008; Bhuyan et al., 2010; Jakhesara et al., 2010; Marques et al., 2011; Vieira et al., 2011; Acosta et al., 2014; Ünal et al., 2014). These microsatellites were BMC1013, CSSM019, CSSM022, CSSM029, CSSM036, CSSM038, CSSM041, CSSM043, CSSM045, CSSM046, CSSM047, ETH3 (D19S2), BM1818, ILSTS005, and ILSTS33.

The optimum annealing temperature for each marker was determined by using gradient PCR thermal cycler (with varied range of annealing temperatures for each marker under the same conditions and for the same samples). Then, the PCR products were tested in 3\% agarose gel through horizontal gel electrophoreses system to determine the best annealing temperature for each marker. Microsatellite markers were tested for amplification using PCR thermal cycler. All microsatellites were successfully amplified except only three markers (CSSM041, ETH3 [D19S2], and ILSTS33). And thus, aggregate of 12 microsatellites were used for analysis of the Egyptian buffalo genome. Chromosome assignment, primers sequence, and the optimum detected annealing temperatures for the analyzed microsatellites are given in Table 1.

PCR amplification was carried out in $10 \mu 1$ reaction mixture. PCR components are shown in Tables 2 and 3 . The PCR protocol was as follows: initial denaturation at $95{ }^{\circ} \mathrm{C}$ for $10 \mathrm{~min}$ followed by 30 cycles of denaturation at 95 ${ }^{\circ} \mathrm{C}$ for $15 \mathrm{sec}$, annealing temperature which was determined for each marker (Table 1) for $1 \mathrm{~min}$ and extension at 
$72{ }^{\circ} \mathrm{C}$ for $1 \mathrm{~min}$, followed by final extension at $72{ }^{\circ} \mathrm{C}$ for $10 \mathrm{~min}$ and hold at $4{ }^{\circ} \mathrm{C}$ for 5 min (Elbeltagy et al., 2008).

Table 1. Chromosome assignment, primers sequence, and the optimum detected annealing temperatures for the analyzed microsatellites

\begin{tabular}{|c|c|c|c|c|c|}
\hline No. & Locus & $\begin{array}{l}\text { Chromosome } \\
\text { assignment }\end{array}$ & Primer sequences $\left(5^{\prime}-3^{\prime}\right)$ & Temp. $\left({ }^{\circ} \mathrm{C}\right)^{*}$ & Reference \\
\hline \multirow{2}{*}{1} & \multirow{2}{*}{ BMC1013 } & \multirow{2}{*}{$3 p$} & F: AAAAATGATGCCAACCAAATT & \multirow{2}{*}{59.4} & \multirow{2}{*}{ FAO (2011) } \\
\hline & & & R: TAGGTAGTGTTCCTTATTTCTCTGG & & \\
\hline \multirow{2}{*}{2} & \multirow{2}{*}{ CSSM019 } & \multirow{2}{*}{$1 \mathrm{q}$} & F: TTGTCAGCAACTTCTTGTATCTTT & \multirow{2}{*}{57} & \multirow{2}{*}{ Moore et al. (1994); FAO (2011) } \\
\hline & & & R: TGTTTTAAGCCACCCAATTATTTG & & \\
\hline \multirow{2}{*}{3} & \multirow{2}{*}{ CSSM022 } & \multirow{2}{*}{$4 q$} & F: TCTCTCTAATGGAGTTGGTTTTTG & \multirow{2}{*}{60} & \multirow{2}{*}{ Moore et al. (1994); FAO (2011) } \\
\hline & & & R: ATATCCCACTGAGGATAAGAATTC & & \\
\hline \multirow{2}{*}{4} & \multirow{2}{*}{ CSSM029 } & \multirow{2}{*}{9} & F: GCTCCATTATGCACATGCCATGCT & \multirow{2}{*}{59} & \multirow{2}{*}{ Moore et al. (1994); FAO (2011) } \\
\hline & & & R: CGTGAGAACCGAAAGCACACATTC & & \\
\hline \multirow{2}{*}{5} & \multirow{2}{*}{ CSSM036 } & \multirow{2}{*}{$1 \mathrm{p}$} & F: GGATAACTCAACCACACGTCTCTG & \multirow{2}{*}{59} & \multirow{2}{*}{ Moore et al. (1994); FAO (2011) } \\
\hline & & & R: AAGAAGTACTGGTTGCCAATCGTG & & \\
\hline \multirow{2}{*}{6} & \multirow{2}{*}{ CSSM038 } & \multirow{2}{*}{11} & F: TTCATATAAGCAGTTTATAAACGC & \multirow{2}{*}{59} & \multirow{2}{*}{ Moore et al. (1994); FAO (2011) } \\
\hline & & & R: ATAGGATCTGGTAACTTACAGATG & & \\
\hline \multirow{2}{*}{7} & \multirow{2}{*}{ CSSM043 } & \multirow{2}{*}{$1 \mathrm{p}$} & F: AAAACTCTGGGAACTTGAAAACTA & \multirow{2}{*}{56} & \\
\hline & & & R: GTTACAAATTTAAGAGACAGAGTT & & Moore et al. (1994); FAO (2011) \\
\hline 8 & CSSM045 & $2 a$ & F: TAGAGGCACAAGCAAACCTAACAC & 53 & Moore et al (1994) FAO(2011) \\
\hline 8 & CSSINU45 & $2 \mathrm{q}$ & R: TTGGAAAGATGCAGTAGAACTCAT & 53 & Moore et al. (1994); FAU (2011) \\
\hline 9 & CSSM046 & 11 & F: TGCACAATCGGAACCTAGAATATT & 50 & More ot al (1094) and EAO (2011) \\
\hline 9 & CSSIVU 40 & 11 & R: GGCTATTAACTGTTTTCTAGGAAT & 39 & Noore el al. (1994) and FAO (2011) \\
\hline 10 & CSSM047 & $3 a$ & F: TCTCTGTCTCTATCACTATATGGC & 56 & Moore et a (1094) FAO (2011) \\
\hline 10 & CSSIVIU4t & $3 \mathrm{q}$ & R: CTGGGCACCTGAAACTATCATCAT & 50 & Nioore et al. (1994), FAU (2011) \\
\hline 11 & RM1818 & $23 * *$ & F: AGCTGGGAATATAACCAAAGG & & \\
\hline 11 & ВМाві8 & $23^{*} \mathrm{k}$ & R: AGTGCTTTCAAGGTCCATGC & 59 & Tantia et al. (2006); Rad et al. (2013) \\
\hline 12 & UI STS 005 & 11 & F: GGAAGCAATGAAATCTATAGCC & 56 & Tontí \\
\hline 12 & ILSTSO05 & 11 & R: TGTTCTGTGAGTTTGTAAGC & 56 & Tantia et al. (2006); FAO (2011) \\
\hline
\end{tabular}

Note. ${ }^{*}$ Temp.: Annealing temperatures in the current study, **chromosome assignment in cattle.

Table 2. PCR components for markers "BMC1013, CSSM019, CSSM022, CSSM043, CSSM045, and CSSM046"

\begin{tabular}{ll}
\hline Component & Volume/sample \\
\hline Master mix (1x) & $5 \mu \mathrm{l}$ \\
Upstream primer (F) & $0.1 \mu \mathrm{l}$ \\
Downstream primer (R) & $0.1 \mu \mathrm{l}$ \\
DNA template & $2 \mu \mathrm{l}$ \\
DNase free water & $2.8 \mu \mathrm{l}$ \\
\hline Total volume & $\mathbf{1 0} \boldsymbol{\mu l}$ \\
\hline
\end{tabular}

Table 3. PCR components for markers “CSSM029, CSSM036, CSSM038, CSSM047, BM1818, and ILSTS005”

\begin{tabular}{ll}
\hline Component & Volume/sample \\
\hline Master mix (1x) & $5 \mu 1$ \\
Upstream primer (F) & $0.2 \mu \mathrm{l}$ \\
Downstream primer (R) & $0.2 \mu \mathrm{l}$ \\
DNA template & $2 \mu 1$ \\
DNase free water & $2.6 \mu \mathrm{l}$ \\
\hline Total volume & $\mathbf{1 0} \boldsymbol{\mu l}$ \\
\hline
\end{tabular}




\subsection{Electrophoresis of PCR Products for Determining the Alleles for Each Marker}

Alleles for each marker were determined by running horizontally $6 \mu$ of the PCR product mixed with $1 \mu 1$ of gel loading dye on $3 \%$ agarose gel electrophoresis and stained by $0.5 \mu \mathrm{l}$ ethidium bromide with concentration of 10 $\mathrm{mg} / \mathrm{ml}$ at $100 \mathrm{~V}$ and $40 \mathrm{~mA}$ for $120 \mathrm{~min} .50 \mathrm{bp}$ and $100 \mathrm{bp}$ DNA ladders were used to estimate alleles size in base pairs (bp). A constant control sample as animal reference which was amplified by "CSSM029" marker was used in all gels to ensure an accurate estimate of allelic size.

\subsection{Statistical Analysis}

Three different programs were used to calculate the genetic parameters. The software of GENETIX 4.05 (Belkhir et al., 1996-2004) was used to estimate allelic frequencies per locus in each population and heterozygozity level $\left(\mathrm{H}_{\mathrm{Nb}}=\right.$ unbiased expected heterozygosity (Nei, 1978) and $\mathrm{H}_{\mathrm{o}}=$ observed heterozygosity). Heterozygosity is defined as the probability that a given individual randomly sampled from a population will be heterozygous at a given locus (Tantia et al., 2006). Number of observed alleles and allelic richness based on a minimum sample size of 9 diploid individuals at each locus within each population were calculated with the FSTAT v.2.9.3.2 program (Goudet, 2002). Number of observed alleles is defined as the actual number of alleles which was detected in the population, whereas, allelic richness is the average number of alleles for each locus. Both of two measures are also referred to as allelic diversity. PIC was computed for each locus using MolKin software version 3.0 (Gutiérrez et al., 2005).

\section{Results and Discussion}

\subsection{Number of Observed Alleles $\left(n_{o}\right)$ and Allelic Richness $\left(n_{a}\right)$}

Number of observed alleles is one of the most important measures of genetic diversity. Estimates of $n_{o}$ at each locus within and over all populations are presented in Table 4 . The results of current study showed that all the analyzed microsatellites were polymorphic as shown from the values of $\mathrm{n}_{\mathrm{o}}$ per locus in the whole population which ranged from 4 for loci CSSM029, CSSM036, CSSM038, CSSM043, CSSM046, and ILSTS005 to 9 for loci BM1818 and CSSM047. In comparison of these findings with other studies on river buffalo for some similar loci, Moioli et al. (2001) and Elbeltagy et al. (2008) concluded similar number of alleles to that obtained for microsatellites CSSM036, CSSM038, and CSSM043 in Egyptian, Italian, and Greek buffalo breeds. Arora et al. (2004) and Kathiravan et al. (2012) clarified comparable number to that observed for the locus CSSM045 in some Indian buffalo breeds. Additionally, analogical allelic number to that mentioned in this study was reported by Kumar et al. (2006) and Soysal et al. (2007) for the markers BM1818 and CSSM047 in some Indian buffalo breeds. Moreover, results of some other studies on different breeds of river buffalo showed as well identical number of alleles to that observed in the present study for some loci but it was higher for others. Ünal et al. (2014) worked on Turkish buffalo and concluded 4 alleles for each of CSSM036, CSSM038, CSSM046, and ILSTS005 loci, and higher number of alleles for CSSM029 and CSSM043 loci (5 and 8 alleles, respectively). Tantia et al. (2006) worked on Indian buffalo and reported 4 alleles for each of CSSM029 and ILSTS005 loci, and higher number of alleles for CSSM043 locus (5 alleles).

As a result of increasing the number of alleles for all analyzed loci (12 microsatellites) over three alleles, these microsatellites could be a useful tool for the estimation of genetic diversity in the Egyptian buffalo, according to one of the most important criteria used to select the appropriate microsatellites for diversity studies which had been suggested by Barker (1994). This denotes presence of high degree of allelic polymorphism in the Egyptian buffalo population. The total number of detected alleles over all loci in the whole population was 64 alleles with overall mean of 5.33. Kafr El-Sheikh population showed the highest number of detected alleles (59 allele with average $=4.92$ ), whereas Sids population showed the lowest number of detected alleles ( 44 allele with average $=$ 3.67). Aminafshar et al. (2008) demonstrated a slightly lower number of alleles across 14 microsatellites for Guilan buffalo population compared to that found in this study. However, Elbeltagy et al. (2008) observed a higher number of alleles across 15 microsatellites for Nile-Delta and Southern-Egypt buffalo populations ( 86 and 84 alleles, respectively). A comparable number of alleles were reported for Banni and Cuban buffalo breeds by Mishra et al. (2009) and Acosta et al. (2014). Other researchers detected a considerably higher number of alleles for both Indian and Egyptian buffalo breeds (Jakhesara et al., 2010; Abou-Bakr et al., 2012; Singh et al., 2017).

Allelic richness $\left(n_{a}\right)$ is one of the most common measures of genetic variability (Leberg, 2002). This measure indicates the potential of a population on long-term for adaptation and persistence (Greenbaum et al., 2014). Increasing the allelic richness of a population can lead to raising its ability for adaptation with environmental changes in future (Caballero \& García-Dorado, 2013). Estimates of allelic richness per locus within and over all populations are given in Table 4. Allelic richness for the whole population ranged between 3.297 for locus CSSM029 and 6.806 for locus CSSM047 with overall mean 4.574. Buffalo population from Kafr El-Sheikh 
region possessed the largest allelic richness (7.331 for CSSM047), whereas, Sids population possessed the least allelic richness (1 for CSSM029). Findings of the current study generally revealed that the highest allelic richness loci were BMC1013, BM1818, CSSM019, and CSSM047.

Table 4. Number of observed alleles $\left(\mathrm{n}_{\mathrm{o}}\right)$ and allelic richness $\left(\mathrm{n}_{\mathrm{a}}\right)$ at each locus within and over all populations:

\begin{tabular}{|c|c|c|c|c|c|c|}
\hline \multicolumn{7}{|c|}{ Observed alleles ( $\left.n_{0}\right)$} \\
\hline Locus & Cairo & Ismailia & Kafr El-Sheikh & Shebeen El-Kom & Sids & Overall Location \\
\hline BMC1013 & 6 & 5 & 5 & 4 & 4 & 6 \\
\hline BM1818 & 5 & 4 & 7 & 6 & 5 & 9 \\
\hline CSSM019 & 6 & 5 & 6 & 5 & 5 & 6 \\
\hline CSSM022 & 4 & 4 & 5 & 3 & 4 & 5 \\
\hline CSSM029 & 4 & 3 & 4 & 3 & 1 & 4 \\
\hline CSSM036 & 4 & 3 & 4 & 4 & 2 & 4 \\
\hline CSSM038 & 4 & 2 & 4 & 3 & 4 & 4 \\
\hline CSSM043 & 4 & 3 & 4 & 3 & 4 & 4 \\
\hline CSSM045 & 4 & 5 & 4 & 3 & 4 & 5 \\
\hline CSSM046 & 2 & 2 & 3 & 3 & 2 & 4 \\
\hline CSSM047 & 6 & 6 & 9 & 6 & 6 & 9 \\
\hline ILSTS005 & 4 & 4 & 4 & 4 & 3 & 4 \\
\hline Overall Loci & 53 & 46 & 59 & 47 & 44 & 64 \\
\hline Mean & 4.42 & 3.83 & 4.92 & 3.92 & 3.67 & $\mathbf{5 . 3 3}$ \\
\hline \multicolumn{7}{|c|}{ Allelic richness $\left(n_{a}\right)^{*}$} \\
\hline Locus & Cairo & Ismailia & Kafr El-Sheikh & Shebeen El-Kom & Sids & Overall Location \\
\hline BMC1013 & 5.543 & 4.984 & 4.935 & 3.989 & 4.000 & 5.457 \\
\hline BM1818 & 4.430 & 3.818 & 5.310 & 5.995 & 4.895 & 6.327 \\
\hline CSSM019 & 5.273 & 4.974 & 5.226 & 4.895 & 4.800 & 5.281 \\
\hline CSSM022 & 3.848 & 3.974 & 4.910 & 3.000 & 4.000 & 4.701 \\
\hline CSSM029 & 3.695 & 2.948 & 3.393 & 2.995 & 1.000 & 3.297 \\
\hline CSSM036 & 3.990 & 3.000 & 3.472 & 3.989 & 2.000 & 3.812 \\
\hline CSSM038 & 3.848 & 2.000 & 3.990 & 3.000 & 3.995 & 3.922 \\
\hline CSSM043 & 3.944 & 3.000 & 3.837 & 2.995 & 3.895 & 3.731 \\
\hline CSSM045 & 3.696 & 4.945 & 3.913 & 3.000 & 3.995 & 4.318 \\
\hline CSSM046 & 1.998 & 1.974 & 2.782 & 2.995 & 2.000 & 3.505 \\
\hline CSSM047 & 5.525 & 5.922 & 7.331 & 5.795 & 5.700 & 6.806 \\
\hline ILSTS005 & 3.871 & 3.984 & 3.512 & 4.000 & 2.995 & 3.735 \\
\hline Mean & 4.138 & 3.794 & 4.384 & $\mathbf{3 . 8 8 7}$ & 3.606 & 4.574 \\
\hline
\end{tabular}

Note. *based on a minimum sample size of 9 diploid individuals.

\subsection{Allele Sizes and Frequencies}

Allele sizes and frequencies for each microsatellite within and over all populations are shown in Tables 5 and 6 . The values of allelic frequency for all the studied loci within the populations ranged from 0.017 for locus BM1818 (in Kafr El-Sheikh population) to 1.000 for locus CSSM029 (in Sids population) whilst values of allele frequency in the whole population ranged from 0.010 for locus BM1818 to 0.782 for locus CSSM029. Results demonstrated the presence of four private alleles at three microsatellite loci with frequencies varied from very low (0.052) to high (0.690). These alleles were the allele $224 \mathrm{bp}$ at locus BMC1013 in Cairo population, the alleles 254 and 272 bp at locus BM1818 in Shebeen El-Kom and Kafr El-Sheikh populations, the allele 164 bp at locus CSSM046 in Kafr El-Sheikh population. In addition, eight rare alleles were observed in six loci (frequency $<0.05$; Tables 5 and 6). These alleles were 256 and 276 bp at locus BM1818 in Kafr El-Sheikh and Cairo populations, the allele $154 \mathrm{bp}$ at locus CSSM019 in Cairo and Kafr El-Sheikh populations, the alleles 195 and 172 bp in Kafr El-Sheikh population at loci CSSM029 and CSSM036 respectively, the alleles 144 and 148 bp at locus CSSM047 in Kafr El-Sheikh population, the allele 190 bp at locus ILSTS005 in Kafr El-Sheikh population. 
Elbeltagy et al. (2008) also observed the existence of exclusive alleles in the Nile-Delta, Southern-Egypt, and Italian buffalo populations but with low frequencies (between 0.01 and 0.17). Ángel-Marín et al. (2010) detected many rare alleles ( 50 alleles) in all the analyzed microsatellites ( 8 loci) for Colombian buffalo herds.

Table 5. Allele sizes and frequencies at loci BMC1013, BM1818, CSSM019, CSSM022, CSSM029, and CSSM036 in all the studied populations

\begin{tabular}{|c|c|c|c|c|c|c|}
\hline Allele size (bp) & Cairo & Ismailia & Kafr El-Sheikh & Shebeen El-Kom & Sids & Overall \\
\hline \multicolumn{7}{|l|}{ Locus BMC1013 } \\
\hline 224 & 0.200 & 0.000 & 0.000 & 0.000 & 0.000 & 0.041 \\
\hline 226 & 0.067 & 0.350 & 0.172 & 0.100 & 0.200 & 0.178 \\
\hline 232 & 0.067 & 0.100 & 0.172 & 0.500 & 0.400 & 0.248 \\
\hline 234 & 0.333 & 0.100 & 0.172 & 0.000 & 0.200 & 0.164 \\
\hline 236 & 0.067 & 0.100 & 0.310 & 0.300 & 0.000 & 0.155 \\
\hline 238 & 0.267 & 0.350 & 0.172 & 0.100 & 0.200 & 0.218 \\
\hline \multicolumn{7}{|l|}{ Locus BM1818 } \\
\hline 252 & 0.400 & 0.500 & 0.448 & 0.000 & 0.400 & 0.349 \\
\hline 254 & 0.000 & 0.000 & 0.000 & 0.250 & 0.000 & 0.050 \\
\hline 256 & 0.000 & 0.000 & 0.017 & 0.150 & 0.000 & 0.033 \\
\hline 268 & 0.067 & 0.000 & 0.086 & 0.100 & 0.000 & 0.051 \\
\hline 270 & 0.133 & 0.227 & 0.069 & 0.000 & 0.200 & 0.126 \\
\hline 272 & 0.000 & 0.000 & 0.052 & 0.000 & 0.000 & 0.010 \\
\hline 274 & 0.367 & 0.000 & 0.276 & 0.200 & 0.050 & 0.178 \\
\hline 276 & 0.033 & 0.227 & 0.052 & 0.150 & 0.100 & 0.112 \\
\hline 278 & 0.000 & 0.045 & 0.000 & 0.150 & 0.250 & 0.089 \\
\hline \multicolumn{7}{|l|}{ Locus CSSMO19 } \\
\hline 144 & 0.133 & 0.273 & 0.207 & 0.000 & 0.400 & 0.203 \\
\hline 146 & 0.167 & 0.091 & 0.069 & 0.250 & 0.050 & 0.125 \\
\hline 148 & 0.533 & 0.182 & 0.414 & 0.400 & 0.000 & 0.306 \\
\hline 150 & 0.067 & 0.273 & 0.138 & 0.100 & 0.300 & 0.176 \\
\hline 152 & 0.067 & 0.182 & 0.138 & 0.200 & 0.200 & 0.157 \\
\hline 154 & 0.033 & 0.000 & 0.034 & 0.050 & 0.050 & 0.034 \\
\hline \multicolumn{7}{|l|}{ Locus CSSMO22 } \\
\hline 208 & 0.067 & 0.273 & 0.138 & 0.000 & 0.556 & 0.207 \\
\hline 210 & 0.267 & 0.364 & 0.276 & 0.300 & 0.222 & 0.286 \\
\hline 212 & 0.333 & 0.091 & 0.241 & 0.400 & 0.000 & 0.213 \\
\hline 214 & 0.333 & 0.273 & 0.207 & 0.300 & 0.111 & 0.245 \\
\hline 216 & 0.000 & 0.000 & 0.138 & 0.000 & 0.111 & 0.050 \\
\hline \multicolumn{7}{|l|}{ Locus CSSM029 } \\
\hline 195 & 0.067 & 0.091 & 0.034 & 0.100 & 0.000 & 0.058 \\
\hline 197 & 0.067 & 0.091 & 0.103 & 0.000 & 0.000 & 0.052 \\
\hline 199 & 0.667 & 0.818 & 0.724 & 0.700 & 1.000 & 0.782 \\
\hline 201 & 0.200 & 0.000 & 0.138 & 0.200 & 0.000 & 0.108 \\
\hline \multicolumn{7}{|l|}{ Locus CSSM036 } \\
\hline 170 & 0.286 & 0.500 & 0.172 & 0.300 & 0.700 & 0.392 \\
\hline 172 & 0.143 & 0.300 & 0.034 & 0.100 & 0.000 & 0.116 \\
\hline 174 & 0.286 & 0.200 & 0.138 & 0.100 & 0.000 & 0.145 \\
\hline 176 & 0.286 & 0.000 & 0.655 & 0.500 & 0.300 & 0.348 \\
\hline
\end{tabular}


Table 6. Allele sizes and frequencies at loci CSSM038, CSSM043, CSSM045, CSSM046, CSSM047, and ILSTS005 in all the studied populations

\begin{tabular}{|c|c|c|c|c|c|c|}
\hline Allele size (bp) & Cairo & Ismailia & Kafr El-Sheikh & Shebeen El-Kom & Sids & Overall \\
\hline \multicolumn{7}{|l|}{ Locus CSSM038 } \\
\hline 179 & 0.300 & 0.545 & 0.259 & 0.500 & 0.300 & 0.381 \\
\hline 181 & 0.233 & 0.000 & 0.207 & 0.200 & 0.100 & 0.148 \\
\hline 185 & 0.067 & 0.000 & 0.276 & 0.000 & 0.200 & 0.109 \\
\hline 187 & 0.400 & 0.455 & 0.259 & 0.300 & 0.400 & 0.363 \\
\hline \multicolumn{7}{|l|}{ Locus CSSM043 } \\
\hline 248 & 0.200 & 0.111 & 0.103 & 0.150 & 0.050 & 0.123 \\
\hline 252 & 0.100 & 0.056 & 0.121 & 0.000 & 0.100 & 0.075 \\
\hline 254 & 0.267 & 0.000 & 0.207 & 0.100 & 0.200 & 0.155 \\
\hline 256 & 0.433 & 0.833 & 0.569 & 0.750 & 0.650 & 0.647 \\
\hline \multicolumn{7}{|l|}{ Locus CSSM045 } \\
\hline 106 & 0.067 & 0.091 & 0.000 & 0.000 & 0.100 & 0.052 \\
\hline 110 & 0.233 & 0.227 & 0.207 & 0.400 & 0.350 & 0.284 \\
\hline 112 & 0.000 & 0.455 & 0.138 & 0.300 & 0.200 & 0.219 \\
\hline 118 & 0.633 & 0.136 & 0.517 & 0.300 & 0.350 & 0.387 \\
\hline 120 & 0.067 & 0.091 & 0.138 & 0.000 & 0.000 & 0.059 \\
\hline \multicolumn{7}{|l|}{ Locus CSSM046 } \\
\hline 160 & 0.000 & 0.091 & 0.000 & 0.200 & 0.000 & 0.058 \\
\hline 164 & 0.000 & 0.000 & 0.690 & 0.000 & 0.000 & 0.138 \\
\hline 166 & 0.800 & 0.909 & 0.241 & 0.700 & 0.400 & 0.610 \\
\hline 168 & 0.200 & 0.000 & 0.069 & 0.100 & 0.600 & 0.194 \\
\hline \multicolumn{7}{|l|}{ Locus CSSM047 } \\
\hline 142 & 0.067 & 0.091 & 0.107 & 0.000 & 0.000 & 0.053 \\
\hline 144 & 0.000 & 0.000 & 0.018 & 0.050 & 0.050 & 0.024 \\
\hline 146 & 0.133 & 0.000 & 0.107 & 0.100 & 0.000 & 0.068 \\
\hline 148 & 0.067 & 0.000 & 0.036 & 0.000 & 0.050 & 0.031 \\
\hline 150 & 0.467 & 0.182 & 0.179 & 0.200 & 0.500 & 0.305 \\
\hline 152 & 0.200 & 0.364 & 0.214 & 0.200 & 0.200 & 0.236 \\
\hline 154 & 0.000 & 0.091 & 0.179 & 0.400 & 0.000 & 0.134 \\
\hline 156 & 0.000 & 0.091 & 0.089 & 0.050 & 0.050 & 0.056 \\
\hline 158 & 0.067 & 0.182 & 0.071 & 0.000 & 0.150 & 0.094 \\
\hline \multicolumn{7}{|l|}{ Locus ILSTSO05 } \\
\hline 188 & 0.286 & 0.700 & 0.310 & 0.333 & 0.600 & 0.446 \\
\hline 190 & 0.143 & 0.100 & 0.034 & 0.222 & 0.000 & 0.099 \\
\hline 192 & 0.500 & 0.100 & 0.483 & 0.333 & 0.300 & 0.343 \\
\hline 194 & 0.071 & 0.100 & 0.172 & 0.111 & 0.100 & 0.111 \\
\hline
\end{tabular}

Figures (from 1 to 4) represent some results of the amplification after running the PCR products of each microsatellite stained by ethidium bromide on $3 \%$ agarose gel.

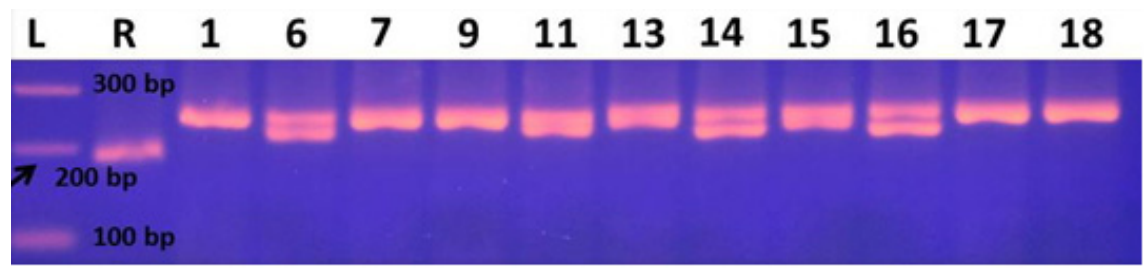

Figure 1. Results of the amplification after running the PCR products of microsatellite BMC1013 stained by ethidium bromide on $3 \%$ agarose gel

Note. L: 100 bp DNA ladder, R: reference animal, and lanes 1, 6, 7, 9, 11, 13, 14, 15, 16, 17, 18 = PCR products of BMC1013 lying between range of 224-238 bp. 


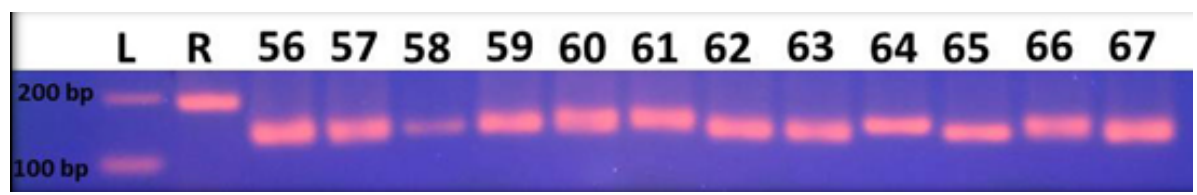

Figure 2. Results of the amplification after running the PCR products of microsatellite CSSM019 stained by ethidium bromide on $3 \%$ agarose gel

Note. L: 100 bp DNA ladder, R: reference animal, and lanes from 56 to $67=$ PCR products of CSSM019 lying between range of 144-154 bp.

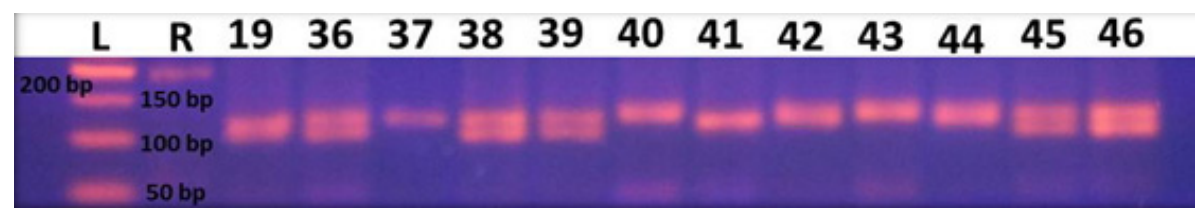

Figure 3. Results of the amplification after running the PCR products of microsatellite CSSM045 stained by ethidium bromide on $3 \%$ agarose gel

Note. L: 50 bp DNA ladder, R: reference animal, and lanes 19, 36, 37, 38, 39, 40, 41, 42, 43, 44, 45, 46 = PCR products of CSSM045 lying between range of 106-120 bp.

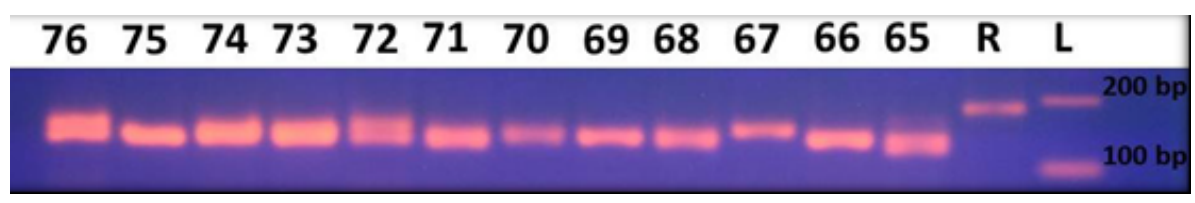

Figure 4. Results of the amplification after running the PCR products of microsatellite CSSM047 stained by ethidium bromide on $3 \%$ agarose gel

Note. L: 100 bp DNA ladder, R: reference animal, and lanes from 65 to $76=$ PCR products of CSSM047 lying between range of $142-158 \mathrm{bp}$.

\subsection{Polymorphic Information Content (PIC)}

The PIC is a parameter indicative of the degree of informative of a marker and another important measure of DNA polymorphism (Abou-Bakr et al., 2012). The high PIC values for markers are indicative of the usefulness of microsatellites for biodiversity evaluation in breed (Jakhesara et al., 2010). Estimates of PIC at every microsatellite locus over all populations are presented in Table 7. PIC estimates were high and ranged between 0.65 (for CSSM029) and 0.92 (for CSSM022) with a mean of 0.82. These values denote high polymorphism of all microsatellites. This according to Botstein et al. (1980) who stated that the locus is highly polymorphic if PIC greater than 0.50 , but it is moderately polymorphic when PIC is more than 0.25 and less than 0.50 , and it is low polymorphic when PIC is lesser than 0.25 . As a result of the high degree of polymorphism at these loci, these microsatellite markers have proved to be very useful in assessing the genetic variability in Egyptian buffalo populations. Results of many studies on Indian and Guilan buffalo breeds showed also high values of PIC (0.52-0.88) for most studied markers (Tantia et al., 2006; Aminafshar et al., 2008; Kataria et al., 2009; Jakhesara et al., 2010; Kathiravan et al., 2012; Singh et al., 2017). Other researchers (Arora et al., 2004; Ángel-Marín et al., 2010; Bhuyan et al., 2010; Vieira et al., 2011; Rad et al., 2013; Ünal et al., 2014) reported varied values of PIC for several markers which ranging between moderate (0.34-0.48) and high (0.51-0.82). 
Table 7. Estimates of polymorphic information content (PIC) per locus across all populations

\begin{tabular}{ll}
\hline Locus & PIC \\
\hline BMC1013 & 0.86 \\
BM1818 & 0.77 \\
CSSM019 & 0.88 \\
CSSM022 & 0.92 \\
CSSM029 & 0.65 \\
CSSM036 & 0.83 \\
CSSM038 & 0.80 \\
CSSM043 & 0.75 \\
CSSM045 & 0.79 \\
CSSM046 & 0.83 \\
CSSM047 & 0.91 \\
ILSTS005 & 0.82 \\
Mean & $\mathbf{0 . 8 2}$ \\
\hline
\end{tabular}

\subsection{Heterozygosity Measure}

Heterozygosity is one of the most important parameters that can give us information about diversity and even the history of a population (Emil \& Marieta, 2012). It includes both observed heterozygosity $\left(\mathrm{H}_{\mathrm{O}}\right)$ and unbiased expected heterozygosity $\left(\mathrm{H}_{\mathrm{Nb}}\right)$. Values of $\mathrm{H}_{\mathrm{o}}$ and $\mathrm{H}_{\mathrm{Nb}}$ per locus for the studied populations are listed in Table 8 .

Table 8. Estimates of observed heterozygosity $\left(\mathrm{H}_{\mathrm{O}}\right)$ and unbiased expected heterozygosity $\left(\mathrm{H}_{\mathrm{Nb}}\right)$ per locus for the studied populations

\begin{tabular}{|c|c|c|c|c|c|c|c|c|c|c|c|c|}
\hline \multirow{3}{*}{ Locus } & \multicolumn{12}{|c|}{ Estimates of heterozygosity within the five populations } \\
\hline & \multicolumn{2}{|c|}{ 1. Cairo } & \multicolumn{2}{|c|}{ 2. Ismailia } & \multicolumn{2}{|c|}{ 3. Kafr El-Sheikh } & \multicolumn{2}{|c|}{ 4. Shebeen El-Kom } & \multicolumn{2}{|c|}{ 5. Sids } & \multicolumn{2}{|c|}{ Mean } \\
\hline & $\boldsymbol{H}_{\boldsymbol{O}}$ & $\boldsymbol{H}_{N b}$ & $\boldsymbol{H}_{\boldsymbol{O}}$ & $\boldsymbol{H}_{N b}$ & $H_{O}$ & $\boldsymbol{H}_{N b}$ & $H_{O}$ & $\boldsymbol{H}_{N b}$ & $\boldsymbol{H}_{\boldsymbol{O}}$ & $\boldsymbol{H}_{N b}$ & $H_{O}$ & $\boldsymbol{H}_{N b}$ \\
\hline $\mathrm{BMC} 1013$ & 0.53 & 0.79 & 0.70 & 0.76 & 0.35 & 0.80 & 0.20 & 0.67 & 0.40 & 0.76 & 0.44 & 0.76 \\
\hline BM1818 & 0.80 & 0.71 & 1.00 & 0.68 & 0.93 & 0.72 & 0.80 & 0.86 & 0.80 & 0.76 & 0.87 & 0.75 \\
\hline CSSM019 & 0.07 & 0.68 & 0.00 & 0.81 & 0.07 & 0.76 & 0.10 & 0.76 & 0.10 & 0.742 & 0.07 & 0.75 \\
\hline CSSM022 & 0.00 & 0.73 & 0.00 & 0.75 & 0.00 & 0.80 & 0.00 & 0.70 & 0.00 & 0.65 & 0.00 & 0.72 \\
\hline CSSM029 & 0.00 & 0.52 & 0.00 & 0.33 & 0.00 & 0.45 & 0.00 & 0.48 & 0.00 & 0.00 & 0.00 & 0.36 \\
\hline CSSM036 & 0.00 & 0.76 & 0.00 & 0.65 & 0.00 & 0.53 & 0.00 & 0.67 & 0.00 & 0.44 & 0.00 & 0.61 \\
\hline CSSM038 & 0.67 & 0.72 & 0.36 & 0.52 & 0.38 & 0.76 & 0.60 & 0.65 & 0.20 & 0.74 & 0.44 & 0.68 \\
\hline CSSM043 & 0.40 & 0.72 & 0.22 & 0.31 & 0.21 & 0.62 & 0.30 & 0.43 & 0.10 & 0.55 & 0.25 & 0.52 \\
\hline CSSM045 & 0.47 & 0.55 & 0.27 & 0.74 & 0.35 & 0.66 & 0.40 & 0.70 & 0.50 & 0.74 & 0.40 & 0.68 \\
\hline CSSM046 & 0.00 & 0.33 & 0.00 & 0.17 & 0.00 & 0.47 & 0.00 & 0.48 & 0.00 & 0.51 & 0.00 & 0.39 \\
\hline CSSM047 & 0.13 & 0.74 & 0.00 & 0.81 & 0.11 & 0.87 & 0.10 & 0.78 & 0.20 & 0.72 & 0.11 & 0.78 \\
\hline ILSTS005 & 0.00 & 0.67 & 0.00 & 0.51 & 0.00 & 0.65 & 0.00 & 0.76 & 0.00 & 0.57 & 0.00 & 0.63 \\
\hline Mean & 0.26 & 0.66 & 0.21 & 0.59 & 0.20 & 0.67 & 0.21 & 0.66 & 0.19 & 0.60 & & \\
\hline
\end{tabular}

The average of $\mathrm{H}_{0}$ across all loci ranged between 0.19 for Sids population and 0.26 for Cairo buffalo population, whereas, the average of $\mathrm{H}_{\mathrm{Nb}}$ ranged between 0.59 for Ismailia population and 0.67 for Kafr El-Sheikh population. It can be observed from these results that values of $\mathrm{H}_{\mathrm{o}}$ are lower than values of $\mathrm{H}_{\mathrm{Nb}}$ for all populations, which denoting depression of heterozygotes in these populations and may be attributable to existence of null alleles and inbreeding. This is partially accord with findings of Mishra et al. $(2008,2009)$ in some Indian buffalo breeds. Elbeltagy et al. (2008) also concluded similar results in both Italian and Delta buffalo populations while opposite trend in the Southern-Egypt buffalo. On the other side, other researchers (El-Kholy et al., 2007; Hassanane et al., 2007) reported overabundant of heterozygotes in Egyptian buffalo populations due to increasing the values of observed heterozygosity than expected heterozygosity. The estimates of observed heterozygosity and expected heterozygosity in the current study were lower than those obtained by some investigators (Elbeltagy et al., 2008; Jakhesara et al., 2010; Abou-Bakr et al., 2012; Attia et al., 2014b; Singh et al., 2017) in Egyptian, Indian, and 
Italian buffalo populations, whereas were higher than those of Moioli et al. (2001) in Egyptian, Italian, and Greek buffaloes.

Across all populations, the average of $\mathrm{H}_{\mathrm{o}}$ varied from 0.00 for both of CSSM022, CSSM029, CSSM036, CSSM046, and ILSTS005 loci to 0.87 for BM1818 locus. The average of $\mathrm{H}_{\mathrm{Nb}}$ ranged between 0.36 for CSSM029 locus and 0.78 for CSSM047. Results in Table 8 showed heterozygosity deficiency at all loci except only one locus (BM1818) which had excess in heterozygotes $\left(\mathrm{H}_{\mathrm{O}}>\mathrm{H}_{\mathrm{Nb}}\right)$. Likewise, Arora et al. (2004) found that the observed heterozygosity was higher than the expected heterozygosity at this locus $(0.45$ vs. 0.39$)$.

\section{Conclusion}

The current study contributes initially to completing the genetic description of the Egyptian buffalo. Genetic characterization of this breed is still incomplete which is very important for conservation decisions and designing future breeding policies. The results indicated that all the microsatellites utilized had high degree of polymorphism and have proved to be very useful in assessing the genetic variability in Egyptian buffalo populations. The findings also revealed depression of heterozygotes in all studied populations and may be attributable to existence of null alleles and inbreeding. Inbreeding can be explained by using very small number of the same bulls from neighboring areas for all the five populations.

\section{References}

Abou-Bakr, S., Ibrahim, M. A. M., Hafez, Y. M., Attia, M., Abdel-Salam, S. M., \& Mekkawy, W. (2012). Genetic characteristics of Egyptian buffalo using DNA microsatellite markers. Egyptian J. Anim. Prod., 49, 121-126.

Acosta, A., Uffo, O., Sanz, A., Obregón, D., Ronda, R., Osta, R., Martin-Burriel, I., Rodellar, C., \& Zaragoza, P. (2014). Genetic characterization of Cuban water buffalo population using microsatellite DNA markers. Buffalo Bulletin, 33, 101-106.

Al-Hosary, A. A. T., Ahmed, L., \& Seitzer, U. (2015). First report of molecular identification and characterization of Theileria spp. from water buffaloes (Bubalus bubalis) in Egypt. Adv. Anim. Vet. Sci., 3, 629-633. https://doi.org/10.14737/journal.aavs/2015/3.12.629.633

Aminafshar, M., Amirinia, C., \& Torshizi, R. V. (2008). Genetic diversity in buffalo population of guilan using microsatellite markers. J Anim Vet Adv, 7, 1499-1502.

Ángel-Marín, P. A., Cardona, H., Moreno-Ochoa, M., \& Cerón-Muñoz, M. F. (2010). Analysis of genetic diversity in Colombian buffalo herds. Revista Colombiana de Ciencias Pecuarias, 23, 411-421.

Arora, R., Lakhchaura, B. D., Prasad, R. B., Tantia, M. S., \& Vijh, R. K. (2004). Genetic diversity analysis of two buffalo populations of northern India using microsatellite markers. J. Anim. Breed. Genet., 121, 111-118. https://doi.org/10.1111/j.1439-0388.2004.00451.x

Athe, R. P., Naha, B. C., Neerasa, G. S., Parthasarathi, B. C., Nukala, R., \& Devara, D. (2018). Molecular markers-characteristics and applications in animal breeding. International Journal of Livestock Research, 8(1), 1-7. https://doi.org/10.5455/ijlr.20170424050432

Attia, M., Abou-Bakr, S., \& Hafez, Y. M. (2014b). Genetic polymorphism of seven microsatellite DNA markers in Egyptian buffalo (pp. 7-12). 2nd International Conference on Biotechnology Applications in Agriculture (ICBAA), Benha University, Moshtohor and Hurghada, 8-12, April 2014, Egypt.

Attia, M., Abou-Bakr, S., \& Nigm, A. A. (2014a). Genetic differentiation and relationship among Egyptian Nile Delta located buffalo using microsatellite markers. Egyptian J. Anim. Prod., 51, 71-77.

Barker, J. S. F. (1994). A global protocol for determining genetic distances among domestic livestock breeds. Proceedings of the 5th World Congress on Genetics Applied to Livestock Production, Guelph and Ontario, Canada, 21, 501-508.

Barker, J. S. F., Moore, S. S., Hetzel, D. J. S., Evans, D., Tan, S. G., \& Byrne, K. (1997). Genetic diversity of Asian water buffalo (Bubalus bubalis): Microsatellite variation and a comparison with protein-coding loci. Anim. Genet., 28, 103-115. https://doi.org/10.1111/j.1365-2052.1997.00085.x

Belkhir, K., Borsa, P., Chikhi, L., Raufaste, N., \& Bonhomme, F. (1996-2004). GENETIX 4.05, logiciel sous Windows TM pour la génétique des populations. Laboratoire Génome, Populations, Interactions, CNRS UMR 5000, Université de Montpellier II, Montpellier, France. Retrieved from http://www.genetix. univ-montp2.fr/genetix/genetix.htm 
Bhuyan, D. K., Sangwan, M. L., Gole, V. C., \& Sethi, R. K. (2010). Studies on DNA fingerprinting in Murrah buffaloes using microsatellite markers. Indian J. Biotech., 9, 367-370.

Botstein, D., White, R. L., Skolnick, M., \& Davis, R. W. (1980). Construction of a genetic linkage map in man using restriction fragment length polymorphisms. Am J Hum Genet, 32, 314-331.

Caballero, A., \& García-Dorado, A. (2013). Allelic diversity and its implications for the rate of adaptation. Genetics, 195, 1373-1384. https://doi.org/10.1534/genetics.113.158410

Elbeltagy, A. R., Galal, S., Abdelsalam, A. Z., El Keraby, F. E., Blasi, M., \& Mohamed, M. M. (2008). Biodiversity in Mediterranean buffalo using two microsatellite multiplexes. Livestock Science, 114, 341-346. https://doi.org/10.1016/j.livsci.2007.10.006

El-Kholy, A. F., Hassan, H. Z., Amin, A. M. S., \& Hassanane, M. S. (2007). Genetic diversity in Egyptian buffalo using microsatellite markers. Arab J. Biotech, 10, 219-232.

Abu El-Magd, M. A., Zaki, A. G., Kahilo, K. A., Barakat, M. E. S., \& Hassan, I. F. (2015). Effect of SNPs in prolactin promoter on milk traits in Egyptian buffalo. $J$ Adv Dairy Res, 3, 128.

Emil, G. S., \& Marieta, C. (2012). Genetic characterization of Romanian local breeds using microsatellite markers. Analysis of Genetic Variation in Animals, 27-44.

Erhardt, G., \& Weimann, C. (2007). Use of molecular markers for evaluation of genetic diversity and in animal production. Arch. Latinoam. Prod. Anim., 15(Supl. 1), 63-66.

FAO (Food and Agriculture Organization of the United Nations). (2011). Molecular genetic characterization of animal genetic resources. FAO Animal Production and Health Guidelines (No. 9). Rome, Italy.

FAO (Food and Agriculture Organization of the United Nations). (2019). Live Animals Data. Rome, Italy.

Goudet, J. (2002). FSTAT version 2.9.3.2, a program to estimate and test gene diversities and fixation indices. Retrieved from http:/www2.unil.ch/popgen/softwares/fstat.htm

Greenbaum, G., Templeton, A. R., Zarmi, Y., \& Bar-David, S. (2014). Allelic richness following population founding events - A stochastic modeling framework incorporating gene flow and genetic drift. PloS One, 9(12), e115203. https://doi.org/10.1371/journal.pone.0115203

Gutiérrez, J. P., Royo, L. J., Álvarez, I., \& Goyache, F. (2005). Molkin v3.0: a computer program for genetic analysis of populations using molecular coancestry information. Journal of Heredity, 96, 718-721. https://doi.org/10.1093/jhered/esi118

Hassanane, M. S., Zaki, A. A., Abou-Bakr, S., Sadek, R. R., \& Nigm, A. A. (2007). Genetic polymorphism of some microsatellites on chromosome seven in the Egyptian buffalo. Egyptian J. Anim. Prod., 44(2), 97-110.

Ibrahim, M. A. (2012). Water buffalo for our next generation in Egypt and in the world. Animal Science, 55, 183-192.

Jakhesara, S. J., Rank, D. N., Kansara, J. D., Parikh, R. C., Vataliya, P. H., \& Solanki, J. V. (2010). Microsatellite DNA typing for assessment of genetic variability in the Mehsana buffalo breed of India. Buffalo Bulletin, 29, 262-269.

Kataria, R. S., Sunder, S., Malik, G., Mukesh, M., Kathiravan, P., \& Mishra, B. P. (2009). Genetic diversity and bottleneck analysis of Nagpuri buffalo breed of India based on microsatellite data. Russ. J. Genet., 45, 826-832. https://doi.org/10.1134/S1022795409070102

Kathiravan, P., Kataria, R. S., \& Mishra, B. P. (2012). Power of exclusion of 19 microsatellite markers for parentage testing in river buffalo (Bubalus bubalis). Mol Biol Rep, 39, 8217-8223. https://doi.org/10.1007/ s11033-012-1669-X

Kumar, S., Gupta, J., Kumar, N., Dikshit, K., Navani, N., Jain, P., \& Nagarajan, M. (2006). Genetic variation and relationships among eight Indian riverine buffalo breeds. Molecular Ecology, 15, 593-600. https://doi.org/10.1111/j.1365-294X.2006.02837.x

Leberg, P. L. (2002). Estimating allelic richness: Effects of sample size and bottlenecks. Molecular Ecology, 11, 2445-2449. https://doi.org/10.1046/j.1365-294X.2002.01612.x

Marques, J. R. F., Martínez, A. M., Costa, M. R., Albuquerque, M. S. M., Quiroz, J., Vega-Pla, J. L., \& Delgado, J. V. (2011). Genetic diversity of Brazilian buffaloes (Bubalus bubalis) using DNA microsatellites. Arch. Zootec., 60, 1213-1221. https://doi.org/10.4321/S0004-05922011000400036 
Mishra, B. P., Kataria, R. S., Bulandi, S. S., Kumar, V., \& Mukesh, M. (2008). Genetic diversity in river buffalo (Bubalus bubalis) breeds of central India using heterologous bovine microsatellite markers. J. Appl. Anim. Res., 33, 159-163. https://doi.org/10.1080/09712119.2008.9706919

Mishra, B. P., Singh, K. P., Chavan, D. B., Sadana, D. K., Kataria, R. S., Kathiravan, P., \& Ahlawat, S. P. S. (2009). Characterization of Banni buffalo of Western India. AGRI, 44, 77-86. https://doi.org/10.1017/ S1014233900002881

Moioli, B., Georgoudis, A., Napolitano, F., Catillo, G., Giubilei, E., Ligda, C., \& Hassanane, M. (2001). Genetic diversity between Italian, Greek and Egyptian buffalo populations. Livestock Production Science, 70, 203-211. https://doi.org/10.1016/S0301-6226(01)00175-0

Moore, S. S., Byrne, K., Berger, K. T., Barendse, W., McCarthy, F., Womack, J. E., \& Hetzel, D. J. S. (1994). Characterization of 65 bovine microsatellites. Mammalian Genome, 5, 84-90. https://doi.org/10.1007/ BF00292333

Moore, S. S., Evans, D., Byrne, K., Barker, J. S. F., Tan, S. G., Vankan, D., \& Hetzel, D. J. S. (1995). A set of polymorphic DNA microsatellites useful in swamp and river buffalo (Bubalus bubalis). Anim. Genet., 26, 355-359. https://doi.org/10.1111/j.1365-2052.1995.tb02674.x

Naqvi, A. N. (2007). Application of molecular genetic technologies in livestock production: potentials for developing countries. Advan. Biol. Res., 1(3-4), 72-84.

Nei, M. (1978). Estimation of average heterozygosity and genetic distance from a small number of individuals. Genetics, 89, 583-590.

Othman, O. E., Mahfouz, E. R., \& El Nahas, S. M. (2012). Genetic variation among Northern and Southern Egyptian buffaloes using polymerase chain reaction-random amplified polymorphic DNA (PCR-RAPD). African J. Biotech., 11, 12808-12813. https://doi.org/10.5897/AJB12.2037

Rad, H. B., Fayazi, J., Amirinia, C., Roshanfekr, H., \& Seydabadi, H. (2013). Parentage tests in Khuzestan buffaloes populations using three microsatellite markers. Int. J. Adv. Biol. Biom. Res., 1, 1414-1422.

Sikka, P., \& Sethi, R. K. (2008). Genetic variability in production performance of Murrah buffaloes (Bubalus bubalis) using microsatellite polymorphism. Indian J. Biotech., 7, 103-107.

Singh, S. G., Taggar, R. K., Chakarborty, D., \& Kour, A. (2017). Molecular genetic characterization of local buffalo population of Jammu and Kashmir region using microsatellite markers. Journal of Animal Research, 7, 1149-1156. https://doi.org/10.5958/2277-940X.2017.00172.3

Soysal, M. I., Ozkan, E., Kok, S., Occidente, M., Tuna, Y. T., Gurcan, E. K., \& Matassino, D. (2007). Genetic characterization of indigenous anatolian water buffalo breed using microsatellite dna markers. Ital. J. Anim. Sci., 6(Suppl. 2), 409-412. https://doi.org/10.4081/ijas.2007.s2.409

Tantia, M. S., Vijh, R. K., Mishra, B., Kumar, S. T. B., \& Arora, R. (2006). Multilocus genotyping to study population structure in three buffalo populations of India. Asian-Aust. J. Anim. Sci., 19, 1071-1078. https://doi.org/10.5713/ajas.2006.1071

Ünal, E. Ö., Soysal, M. İ., Yüncü, E., Dağtaş, N. D., \& Togan, İ. (2014). Microsatellite based genetic diversity among the three water buffalo (Bubalus bubalis) populations in Turkey. Arch. Anim. Breed., 57, 1-12. https://doi.org/10.7482/0003-9438-57-008

Vieira, J. N., Teixeira, C. S., Kuabara, M. Y., \& de Oliveira, D. A. A. (2011). DNA microsatellites for genetic identification in Brazilian Murrah water buffaloes. Acta Veterinaria Brasilica, 5, 364-367. https://doi.org/10.22256/pubvet.v5n2.1004

Zhang, Y., Sun, D., Yu, Y., \& Zhang, Y. (2008). Genetic variation and divergence among swamp buffalo, river buffalo and Cattle: A microsatellite survey on five populations in China. Asian-Aust. J. Anim. Sci., 21, 1238-1243. https://doi.org/10.5713/ajas.2008.70746

\section{Copyrights}

Copyright for this article is retained by the author(s), with first publication rights granted to the journal.

This is an open-access article distributed under the terms and conditions of the Creative Commons Attribution license (http://creativecommons.org/licenses/by/4.0/). 